\title{
Conditional Probability and the Identification of Bacteria: a Pilot Study
}

\author{
By W. DYBOWSKI* \\ United States Air Force Laboratory Centre, United States Air Force Hospital, \\ South Ruislip, Middlesex \\ AND D. A. FRANKLIN $\dagger$ \\ Medical Automation Experimental Unit, University College Hospital, \\ 69-71 Chenies Mews, London, W.C. I
}

(Accepted for publication 25 June 1968)

SUMMARY

The use of a conditional probability model for the identification of bacteria is illustrated by a pilot study on a group consisting mainly of bacteria of the family Enterobacteriacae. It is shown that such models may be untrustworthy unless more stringent criteria are used about the basic data and about the results than is normally the case in studies of this kind, including the present one.

\section{INTRODUCTION}

In recent years the possibilities for mathematical methods in medicine have been increasingly realized. The incentive to investigate and use quantitative approaches has been greatly stimulated by the development of the electronic digital computer, since many of the calculations involved in medical problems are impractical by manual means. An early target for mathematical investigation was clinical diagnosis (e.g. Ledley \& Lusted, 1959; Warner, Toronto, Veasey \& Stephenson, I96I). This interest has continued, and a recent MEDLARS search produced 265 English, French and German references since 1963 under the heading of computers in diagnosis, identification and classification of disease, and bacteriology.

A common approach in clinical work has been to use Bayes' theorem or Fisher's likelihood (Kendall \& Stuart, 1963a) to determine how seriously any given disease should be regarded as the cause of the signs and symptoms observed. For some reason, however, these methods have not been investigated to the same extent in bacteriology as in clinical medicine. An exception is the work of Möller (1962), and of Rypka, Clapper, Bowen \& Babb (1967), who refer to a Bayesian programme for bacterial identification. This lack of investigation is to be regretted; bacteriology might well prove to be a more rewarding area than clinical medicine for the application of these methods, because of the reproducibility of bacteriological reactions and the opportunities for close control. Perhaps the stumbling block has been the lack of quantitative data which these theories demand; but it seemed to the present authors that even

* Now retired. Present address: 17 Brouncker Road, Acton, London, W. 3.

$\dagger$ Present address: Medical Research Council Computer Services Centre, Derbyshire House, St Chad's Street, London, W.C. I. 
inspired approximations (numerically speaking) might be of some use, and the present pilot study was therefore undertaken. Although the calculations could conceivably have been carried out manually, it was felt that the greater flexibility, reliability and processing speed of a computer were needed, and a programme was written for the National-Elliott 803 .

The work was begun in the latter half of 1962 . A preliminary account of it was given in an article by Payne (1963). However, that account was merely expository and, as will be seen, following further investigations the present article comes to somewhat different conclusions concerning the methodology and the results.

\section{METHODS}

\section{Bacteria studied}

The bacteria chosen for study were largely members of the family Enterobacteriacae because data about this group were more readily available in a tabular form. Our data sources were Kauffmann (I954), Edwards \& Ewing (I962) and Bergey's Manual (Breed, Murray \& Smith, 1957). The list of bacteria is given in Table I. In the study it was assumed that any unknown submitted for analysis was a strain of one of the bacteria in this list.

\section{Tests used}

The tests chosen were decided on the twin bases of available data and bacteriological experience. They are listed in Table 2.

Table I. List of bacteria in the reference set

$\begin{array}{lll}\text { Alcaligenes faecalis } & \text { Proteus rettgeri } & \text { Salmonella paratyphi B } \\ \text { Alkalescens dispar group } & \text { P. vulgaris } & \text { S. paratyphi C } \\ \text { Arizona arizonae } & \text { Providencia A } & \text { S. pullorum } \\ \text { Bethesda-Ballerup group } & \text { Providencia B } & \text { S. sendai } \\ \text { Enterobacter aerogenae } & \text { Pseudomonas aeruginosa } & \text { S. typhi } \\ \text { Enterobacter cloacae } & \text { Salmonella choleraesuis } & \text { S. typhimurium } \\ \text { Escherichia coli } & \text { S. choleraesuis var. kunzendorf } & \text { Shigella boydii } \\ \text { E. freundii } & \text { S. decatur } & \text { S. dysenteriae } \text { I } \\ \text { Hafnia alvei } & \text { S. gallinarum } & \text { S. dysenteriae 2 } \\ \text { Klebsiella pneumoniae } & \text { S. gallinarum } \text { var. duisburg } & \text { S. dysenteriae (other serotypes) } \\ \text { K. rhinoscleromatis } & \text { S. miami } & \text { S. flexneri } \\ \text { Proteus mirabilis } & \text { S. newport } & \text { S. sonnei } \\ \text { P. morganii } & \text { S. paratyphi A } & \end{array}$

Table 2. List of tests in the reference set

Gelatin liquefaction

Hydrogen sulphide production

Indole production

Methyl red

Motility

Potassium cyanide (growth in)

Sodium citrate utilization

Urea hydrolysis

Voges-Proskauer
Acid or acid+gas from

Adonitol

Arabinose

Glucose

Dulcitol

Inositol

Lactose

Mannitol

Rhamnose

Salicin

Sorbitol

Sucrose

Xylose 


\section{Mathematical theory}

Of the two approaches considered, i.e. likelihood and Bayesian probability, it was decided not to use the Bayesian approach because of $(a)$ the controversial question of the validity and role of prior probabilities in diagnosis and identification (Lipkin, 1964; Boyle et al. 1966); (b) the impossibility of estimating them in this case. These points are discussed later. We recognize, however, that both approaches are subjects for debate amongst statisticians and others, and those readers who dislike the terms 'probability' or 'likelihood' may prefer to think of the quantities concerned merely as frequency ratios.

The application of the likelihood concept to the present study runs as follows: Suppose that in past experience, out of a total of $N$ established strains of a certain bacterium, $N_{1}$ strains had responded with a specific result, $r_{1}$ say, to a particular test, $t_{1}$. We define the likelihood of obtaining the specified result to the test with a further strain of the bacterium as $N_{1} / N$, i.e. the proportion of strains which in the past has given that result. This is also known as the conditional probability of obtaining the particular result given the test and the strain.

If with a second test, $t_{2}$ say, the proportion of the same $N$ strains giving some other specified result $r_{2}$ is $N_{2} / N$, the likelihood that a further strain of the bacterium will give the joint pattern $r_{1}, r_{2}$ as results for tests $t_{1}, t_{2}$ is taken to be $N_{1} / N \times N_{2} / N$.

The extension to more than two tests is clear. If tests $t_{1}, t_{2}, \ldots, t_{m}$ were performed on $N$ established strains of a given bacterium, and $N_{1}$ gave result $r_{1}$ for test $t_{1}, N_{2}$ gave result $r_{2}$ for test $t_{2}$, etc., the likelihood of obtaining the pattern $r_{1}, r_{2}, \ldots, r_{m}$ if the set of tests $t_{1}, t_{2}, \ldots, t_{m}$ is performed on a further known strain of the organism is taken to be

$$
\frac{N_{1}}{N} \times \frac{N_{2}}{N} \ldots \frac{N_{m}}{N}
$$

This represents the likelihood of obtaining a specific test pattern given a known strain. Fisher's theory applied to the present case states that when faced with a choice of possible suspects arising from a given pattern of results with an unknown strain, we should make our decision by computing the likelihoods for the observed pattern for each of the possibilities, and then choose that bacterium which gives the greatest likelihood. In other words, we are to choose the suspect giving 'the greatest probability to the observed event' (Kendall \& Stuart, $1963 a$ ). In medical work, however, a choice of alternatives often involves a comparison of the risks to the patient entailed in each alternative. For example, selection of the most likely organism in a bacteriological investigation may dictate treatment with an antibiotic noted for its unpleasant or even dangerous side effects, whereas the next most likely would require something much milder and safer. Some workers investigating the clinical applications of likelihood or Bayesian probability have attempted to allow for similar considerations by requiring that a given degree of likelihood or probability ratio between first and second suspects be exceeded before accepting that an identification has been made (e.g. Fitzgerald \& Williams, I964; Boyle et al. 1966).

An important assumption of the theory is that the tests must all be statistically independent. Two tests are said to be independent when the outcome of either of them is unaffected by the outcome of the other. It was assumed in the present study that the tests satisfied this assumption. 
If sufficient statistics were available, then the ratios in equation (I) could be clothed in realistic numerical form. For example, if we knew that in 1000 verified strains of Salmonella typhi, 54I of them had failed to ferment arabinose, the ratio to use in the event of a negative result when an unknown organism was tested for fermentation of arabinose would be $54 \mathrm{I} / 1000=0.54 \mathrm{I}$; if the result were positive the ratio to use would be (1000-54I)/1000 $=0.459$. However, data such as these do not exist as yet, and it was necessary to use some relatively arbitrary values for the ratios concerned. It was decided that for tests having only two possible outcomes (or 'two-valued' tests as they were called), if a result was 'very common' or 'nearly always expected' for a particular bacterium and test, the ratio value to use would be 0.95 , with the corre-

\section{Table 3. Part of the matrix of likelihoods}

\begin{tabular}{llcccccc} 
& & $\begin{array}{c}\text { Escherichia } \\
\text { coli }\end{array}$ & $\begin{array}{c}\text { Bethesda- } \\
\text { Ballerup }\end{array}$ & $\begin{array}{c}\text { Proteus } \\
\text { vulgaris }\end{array}$ & $\begin{array}{c}\text { Proteus } \\
\text { mirabilis }\end{array}$ & $\begin{array}{c}\text { Provi- } \\
\text { dencia A }\end{array}$ & $\begin{array}{c}\text { Provi- } \\
\text { dencia B }\end{array}$ \\
\multirow{3}{*}{ Motility } & + & 0.95 & 0.05 & 0.95 & 0.05 & 0.95 & 0.95 \\
& + & 0.05 & 0.95 & 0.05 & 0.95 & 0.05 & 0.05 \\
$\mathbf{H}_{2} \mathrm{~S}$ & + & 0.5 & 0.95 & 0.95 & 0.95 & 0.95 & 0.95 \\
& + & 0.5 & 0.05 & 0.05 & 0.05 & 0.05 & 0.05 \\
\multirow{3}{*}{ Gelatin } & + & 0.05 & 0.95 & 0.95 & 0.95 & 0.05 & 0.05 \\
& + & 0.95 & 0.05 & 0.05 & 0.05 & 0.95 & 0.95 \\
Glucose & No change & 0.025 & 0.025 & 0.025 & 0.025 & 0.025 & 0.025 \\
& Acid & 0.025 & 0.025 & 0.025 & 0.025 & 0.025 & 0.950 \\
& Acid +gas & 0.950 & 0.950 & 0.950 & 0.950 & 0.950 & 0.025 \\
\multirow{2}{*}{ Mannitol } & No change & 0.025 & 0.025 & 0.950 & 0.950 & 0.950 & 0.475 \\
& Acid & 0.025 & 0.025 & 0.025 & 0.025 & 0.025 & 0.475 \\
& Acid +gas & 0.950 & 0.950 & 0.025 & 0.025 & 0.025 & 0.050
\end{tabular}

sponding uncommon result being valued at 0.05 . A more variable result was given a value of 0.5 , its corresponding opposite being given the same value. Similar considerations were applied to tests having three possible outcomes ('three-valued' tests). A section of the matrix of values used is given in Table 3. The only justification we can put forward for the numbers used is that they appeared reasonable and led to fairly good results.

As an example of the use of Table 3, consider the case where tests for production of indole, for motility and for production of $\mathrm{H}_{2} \mathrm{~S}$ are applied to an unknown organism which is believed to belong to either the Providencia subgroup A or B or the Escherichia coli group. Let the results be,++ and - for the three tests respectively. Then, from Table 3, the likelihood of the organism belonging to Providencia subgroup A is $0.95 \times 0.95 \times 0.95=0.857$ (and similarly for Providencia subgroup B), and the likelihood for Escherichia coli is $0.95 \times 0.5 \times 0.95=0.45 \mathrm{I}$. As far as these tests go, the maximum likelihood approach would then have us choose one of the Providencia subgroups as the most likely possibility, rather than Escherichia coli. Further tests would then be needed to differentiate between the two subgroups.

In the example given above, so few tests or such a ratio of likelihoods would certainly be felt to be completely inadequate for purposes of differentiation. However, the questions of how many tests are needed for adequate differentiation, which ones to use, and what the criterion for a decision should be are points which must be settled if 
a quantitative model for identification is to be meaningful. Some attempt was made to cope with these aspects, but the problems were by no means solved, and indeed very little consideration appears to have been given to them by any other workers attempting to apply probability theory to identification in this or related areas of medicine or biology.

\section{Percentage relative likelihood}

A difficulty which arises immediately in using likelihood is the sizes of the likelihoods. Likelihood diminishes with increasing number of tests, and even with as few as 10 tests one may be dealing with quantities of the order of $10^{-3}$, $10^{-4}$ or less. To avoid having to work with such small quantities, it was decided to express the scores arising from equation (I) above by scaling them so that the maximum for any particular set of suspects had a value of $100 \%$. This quantity was called the percentage relative likelihood (see also Boyle et al. 1966). Thus, in the example given above, the percentage relative likelihood of each Providencia subgroup is $(0.857 / 0.857) \times 100 \%=100 \%$ and that of Escherichia coli is $(0.45 \mathrm{I} / 0.857) \times 100 \%=52.6 \%$.

\section{Modal likelihood fraction}

At an early stage in the study it became clear that the use of likelihood or relative likelihood on its own had some serious shortcomings. Both quantities assume that probabilities or likelihoods are comparable even when they apply to different populations. Again, it has already been noted that likelihood is in general a small quantity; when using it, one is always faced with having to differentiate between a likelihood which is small because it is inherently small for the particular suspect and set of tests, and one which is small, because the suspect is unlikely or atypical on the given test results. It is not enough to say that the likelihood of $\mathrm{A}$ is so many times greater or smaller than that of B; we need to know also the relative status of the likelihood of $A$ within the set of likelihoods possible for A with the given tests, and similarly for B. Relative likelihood preserves the order of the set of suspects, but it masks the difficulties of small likelihoods and likelihood distributions referred to above. To see this at work, consider an example from one of the cases tested. The test results were

\begin{tabular}{|c|c|c|c|}
\hline Indole production & - & Lactose & No change \\
\hline Motility & + & Mannitol & Acid + gas \\
\hline Hydrogen sulphide & + & Rhamnose & Acid+gas \\
\hline Sodium citrate utilization & + & Dulcitol & Acid + gas \\
\hline Gelatin hydrolysis & - & Arabinose & Acid + gas \\
\hline Potassium cyanide (growth in) & - & & \\
\hline Xylose & Acid + gas & Sorbitol & Acid + gas \\
\hline Sucrose & No change & Inositol & No change \\
\hline Possible orga & & \multicolumn{2}{|c|}{$\begin{array}{l}\% \text { Relative } \\
\text { likelihood }\end{array}$} \\
\hline $\begin{array}{l}\text { Salmonella newport } \\
\text { S. paratyphi } C \\
\text { S. paratyphi } B \\
\text { S. typhimurium } \\
\text { S. choleraesuis var. kunzendorf }\end{array}$ & & & $\begin{array}{r}00 \cdot 00 \\
50 \cdot 00 \\
6 \cdot 58 \\
6 \cdot 58 \\
1 \cdot 32\end{array}$ \\
\hline
\end{tabular}

On these results, Salmonella newport is twice as likely as $S$. paratyphi $C$ (the correct answer) and nearly 16 times as likely as $S$. paratyphi $B$ or $S$. typhimurium. But on further examination of the matrix of values, it became clear that the absolute likelihoods for the first four organisms given above were the greatest possible with the given tests. 
Moreover, the procedure for selecting further tests (see below) showed that none of the remaining tests had any power to increase the discrimination. In other words, because $S$. paratyphi $C$ and the others are more variable in their behaviour than $S$. newport as far as the given tests are concerned, they were being discriminated against because of their variability. This is clearly unrealistic. Other implications of this situation will be raised in the Discussion. Theory is available which could perhaps cope with this situation to some extent (e.g. Kendall \& Stuart $1963 b$ ), but at the time of this study the authors were (and still are) unaware of any theory which would deal completely with the mixture of two-valued and three-valued tests being used. An empirical approach was therefore used which, nevertheless, has some statistical justification, as will be shown.

This approach was to compute what was called the modal likelihood fraction for each suspect. This was defined as

$$
\frac{\text { likelihood for the given set of test results }}{\text { maximum likelihood possible for that bacterium with the given tests }} \text {. }
$$

Thus in the previous example, the modal likelihood fraction for each of Salmonella newport, $S$. paratyphi $C, S$. paratyphi $B$ and $S$. typhimurium was found to be $\mathrm{I} \cdot \circ$. This showed that the likelihoods for each were the best possible with the given tests, and implied that it would be misleading to choose $S$. newport in preference to $S$. paratyphi $C$ or even $S$. typhimurium, on the likelihoods given. Further tests were undoubtedly needed.

If we regard the ratios $N_{1} / N$ in (I) as probabilities, the modal likelihood fraction expresses the ordinate, corresponding to the actual test results in the multivariate distribution associated with a given bacterium for a given set of tests, as a fraction of the mode of the distribution, hence the name. For a 'well-defined' organism, i.e. sharply differentiable over a set of tests, the distribution should be unimodal and the bulk of it should lie around the mode; the more evenly the distribution lies, the more diffuse the organism. On the assumption of reasonably well-defined organisms, the modal likelihood fraction is an attempt to compare the rarity of patterns within their distributions.

\section{Selection of further tests}

As well as using the matrix of ratios for the selection of possibilities, an attempt was made to use it for the selection of further tests aimed at improving the separation between suspects. Later work has shown that the method does not necessarily lead to an improvement in relative likelihood separation between suspects. However, a brief account of the approach is worthwhile in that it bears some resemblance to the method recently described by Rypka et al. (1967) and it did prove possible to use it to discover the point at which further testing could lead to no improvement at all in separation.

Consider in Table 3 the example of the reactions for gelatin liquefaction and $\mathrm{H}_{2} \mathrm{~S}$ production of the Bethesda-Ballerup group, Proteus vulgaris and $P$. mirabilis. We see that the gelatin liquefaction test cannot distinguish between the two Proteus species: the distribution of values with respect to positive and negative outcomes is exactly the same for both organisms, and, whatever the test result, we would gain no additional discrimination. However, testing for gelatin liquefaction is clearly of use in distinguishing the Bethesda group from the two Proteus species; a common result for one is uncommon for the other, and vice versa. On the same lines, the test for $\mathrm{H}_{2} \mathrm{~S}$ production 
is useless for distinguishing between any of the organisms. The reasoning is the same with three-valued tests: testing for fermentation of glucose adds nothing to the discrimination between the three organisms, whereas the mannitol fermentation test can help to some extent.

This reasoning led to consideration of the absolute difference between corresponding ratios as a measure of discriminating power. The power of a test to distinguish between two bacteria was defined as the sum of the absolute differences between corresponding ratios for all possible outcomes to the test. Thus, for example, the power of the gelatin liquefaction test to distinguish between the Bethesda group and Proteus vulgaris would be:

$$
|0.05-0.95|+|0.95-0.05|=\mathrm{I} \cdot 8 \text {, }
$$

and that of mannitol fermentation:

$$
|0.025-0.950|+|0.025-0.025|+|0.950-0.025|=\mathrm{I} \cdot 85
$$

(where we use the normal mathematical notation for an absolute value: $|x|=x$ if $x$ is positive, $|x|=-x$ if $x$ is negative). This would imply that mannitol fermentation is slightly better than gelatin liquefaction in this case.

For a set of bacteria, the power of a test to distinguish between them was obtained by making the calculation for all possible pairs in the set and summing the results. This consideration of all possible pairs of differences is comparable with the procedure of Rypka et al. (1967) and would lead to similar results in the case of non-variable characters. It also enlarges their method to multiple-valued tests. However, the variability of the characters led to a more complex situation than that envisaged by Rypka et al. and in fact it can be shown that with two-valued tests the procedure cannot be relied on to lead to an improvement in relative likelihood separation. We have been unable so far to demonstrate an analogous result for three-valued tests, but it is almost certain that the situation is the same for these also. The 'Discriminating Power', as it was called, had some usefulness; it gave a measure of the spread of the distribution of ratios for a test over a set of bacteria and was able to indicate when a test could not discriminate at all over a set of suspects. It also gave more power to a 'good' three-valued test than to a 'good' two-valued one, corresponding with what one would expect on heuristic grounds. However, apart from using it to decide when tests were useless, the method was not investigated to any depth and it is not proposed to discuss it further, though the Discussion shows that some method is necessary for determining the sequence in which tests are carried out.

\section{Short description of programme and procedure}

The programme was designed to take in first as data the matrix of values; each row was sum-checked to guard against reading and data-punching errors. Once the matrix had been read in, the details of the individual case followed. The first of these was a number to indicate whether the case was a new one or a continuation of a previous calculation. If a continuation, the programme expected the data output at the end of the previous run for this case before it would read in the new data, otherwise the programme went straight into reading in the new data. The new data consisted of a set of test numbers (each test was given a number between 0 and 20 inclusive), each test number being followed by a result number. With two-valued tests, this was zero for + and $\mathrm{I}$ for - ; with three-valued ones, 'no change' was coded zero, 'acid' 
coded I, and 'acid+gas' coded 2. After the test/result statements came parameters to determine how many suspects to print out, and how many further tests to select. The programme then did its calculations and printed its answers. Then, according to the user's decision on studying the answers, it could either return to take in results of further tests for the same case or data for an entirely new case. There were various refinements built in-e.g. a case was automatically ended when only one bacterium was printed out or when there were no further tests with any discriminating power. The calculation for any given set of data took 20 to $40 \mathrm{sec}$., depending on the number of tests and the values of the various parameters.

The intention in this study was not so much to achieve identifications as to investigate the outcome of taking the $100 \%$ relative likelihood suspect to be the correct answer at various stages of testing. This is the straight maximum likelihood approach; as already noted, other workers have required arbitrary levels of likelihood ratio between first and second suspects to be exceeded before accepting the most likely suspect as the answer. There was therefore no particular criterion used for terminating specific investigations except when either the odds of first choice to second choice became so high that it appeared extremely unlikely that further tests would make any difference, or else the procedure for selection of further tests showed that no further discrimination was possible.

\section{RESULTS}

\section{Cases investigated}

Apart from several test cases used during the programme development, I 2 cases were investigated. These consisted of a known specimen of each of: Salmonella typhimurium, Shigella dysenteriae (not serotype I or 2), Salmonella paratyphi $A, S$. paratyphi $B$ and $S$. paratyphi $C$, Arizona arizonae, Escherichia coli, Shigella boydii, S. sonnei, Klebsiella pneumoniae, Providencia subgroup A and Proteus mirabilis. In each case an independent Reference Laboratory determination was available for comparison with the computed result. An example of the process (which also illustrates the output from the programme) is given in the Appendix. Table 4 gives a summary of results for the 12 cases.

\section{DISCUSSION}

Even with so few cases, the examples already discussed and the results given in Table 4 reveal some undesirable features of the use of likelihood for this type of work. Further points (see below) indicate that methodological deficiencies can become extremely serious. It is worth noting that Bayes' theorem shares these deficiencies, over and above the difficulties arising out of the use of prior probabilities. The first point has already been indicated, namely that when using likelihood alone, the more variable organisms are discriminated against, because of their variability. What this amounts to is that a given set of tests may have insufficient discriminating power to effect a conclusive separation between the organisms it is supposed to cover, even under the most favourable circumstances. The operative words are 'insufficient' and 'conclusive', because the user has at least two options open to him: (I) to decide in advance what will be an acceptable likelihood ratio between first and second suspects for a decision and then check (by means of modal likelihood fraction or some other method) that the set of tests can meet this norm under the most favourable circumstances or under some defined deviation from them; (2) to accept the test set as it 
stands, and determine the worst misclassification which can occur, again under some defined set of circumstances, and then use the likelihood ratio level for which this occurs as the level to be exceeded before a decision can be made. Thus, if on the Salmonella example given earlier, this strain had contributed to the basic table of likelihoods and the true answer was known to be Salmonella typhimurium, and it was also known that the ratio of relative likelihoods of $100: 6.58$ was the highest for any misclassification under optimum circumstances, then the criterion would be that the ratio between first and second suspects must be at least $100: 6.58$ before a decision could be made.

Whatever procedure is adopted, the blind use of a set of tests combined with either simple maximum likelihood choice or an arbitrary discrimination level between likelihoods is untenable and inconsistent. Unfortunately this appears to have been the standard procedure in all the published work known to the authors on the use of conditional probability for diagnosis and identification, not just in bacteriology but in medicine generally. Criteria for discrimination are not based on a critical evaluation of the basic data, as they should be.

A second criticism which can be made is that results depend on the order in which tests are done. For instance, in case 5 (Table 4 ) the correct organism started off after five tests as the 'most likely' (though it was in fact one of a set of seven suspects all with $100 \%$ relative likelihood); after two more tests it had a relative likelihood of $50 \%$, becoming $100 \%$ again after eight more tests. Had the tests been made in a different order with different groupings, the sequence of percentages would have been different: the correct organism would have remained at $100 \%$ throughout. It is interesting to see from Table 4 that the complete set of tests was in this case shown to be inadequate for an unequivocal separation on the given results. In this case, even if one were prepared to accept a 2 : I ratio as a basis for decision, confirmatory tests would probably have been desirable after the $50 \%$ relative likelihood level had been reached, and a mistaken identification would have been avoided.

But whereas in this example the effect of the sequence was unimportant, in other examples it was more serious, and this brings the third criticism, the possible vulnerability of the procedure to errors in data. In case 2 (Table 4), the correct result started off with a relative likelihood of less than $10 \%$ after five tests; the level rose to $21 \%$ after six more tests and remained at this level through four confirmatory tests. Only with the final three tests did the identification become dubious with a rise to $84 \%$. Had one been discriminating at a ratio of 5 : I (not an unreasonable level, perhaps), it would have been tempting to consider the identification confirmed after the fourth set of tests. The point about this example is that one of the test results was found later to have been erroneously coded. The result for sucrose fermentation was coded as 'acid + gas', whereas the true result was 'no change', and the systematic depression of the results for Salmonella paratyphi $A$ was due entirely to this one error. With the correct result for the test, the outcome after the second group of tests would have been $100: 25$ in favour of $S$. paratyphi $A$ against Escherichia coli, with a modal likelihood fraction of 0.013 for the former; this ratio would have persisted until the fifth group of tests, when the final ratio between these two would have been $100: 6$. The original results favoured $E$. coli, and, what is more, had these results been taken in a different order, the ratio of $100: 84$ would have been arrived at earlier in the sequence, giving a final 'confirmed' ratio of $100: 84$ for Escherichia coli against Salmonella paratyphi $A$. Another case (number 9) had an unusual result (urea hydrolysis negative) 
Table 4. Summary of twelve cases

The numbers in the columns marked 'Test set' indicate whether the test concerned was among the first group of tests used, or the second, or the third etc. The numbers in the columns marked ' $\%$ r.l.' and ' $m .1 . f$.'-corresponding to 'percentage relative likelihood' and 'model likelihood fraction' respectively-indicate the values of these quantities for the correct suspect after the corresponding test set had been completed. Thus, for Case I, alleged to be Shigella boydii, the percentage relative likelihood for $S$. boydii at the completion of the second group of tests was $13.2 \%$, and the modal likelihood fraction was $I \cdot 00$.

Case no. ...

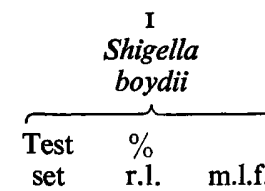

Tests

set r.l. m.l.f.

3

$\overbrace{\begin{array}{c}\text { Test } \\ \text { set }\end{array} \quad \text { r.l. } \quad \text { m.l.f. }}^{\text {S. typhimurium }}$

\section{4}

S. paratyphi C

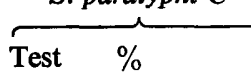

Gelatin hydrolysis

$\mathrm{H}_{2} \mathrm{~S}$ produced

Indole produced

Methyl red

Motility

KCN growth

Sodium citrate

Urea hydrolysis

Voges-Proskauer

Adonitol

Arabinose

Glucose

Dulcito

Inositol

Lactose

Mannitol

Rhamnose

Salicin

Sorbito

Sucrose

Xylose

Total no. of tests

per case

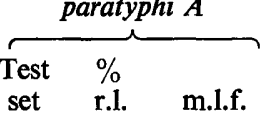

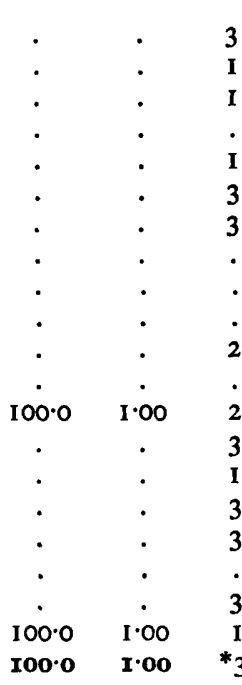

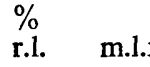

$\begin{array}{cc}\cdot & \cdot \\ \cdot & \cdot \\ \cdot & \cdot \\ \cdot & \cdot \\ \cdot & \cdot \\ \cdot & \cdot \\ \cdot & \cdot \\ \cdot & \cdot \\ \cdot & \cdot \\ 50 \cdot 0 & 1 \cdot 00 \\ \cdot & \cdot \\ \cdot & \cdot \\ . & \cdot \\ . & \cdot \\ . & \cdot \\ 100 \cdot 0 & 1 \cdot 00 \\ 50 \cdot 0 & 1 \cdot 00\end{array}$
5

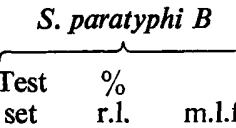

Shigella dysenteriae (other)

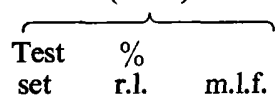

set r.l. m.l.f.

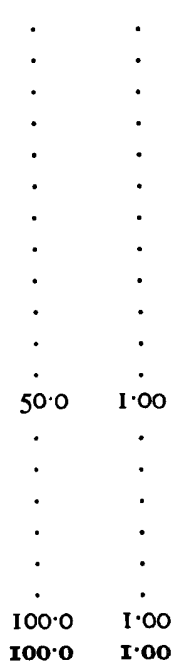

$100.0 \quad 0.026$ 
Table 4 (cont.)

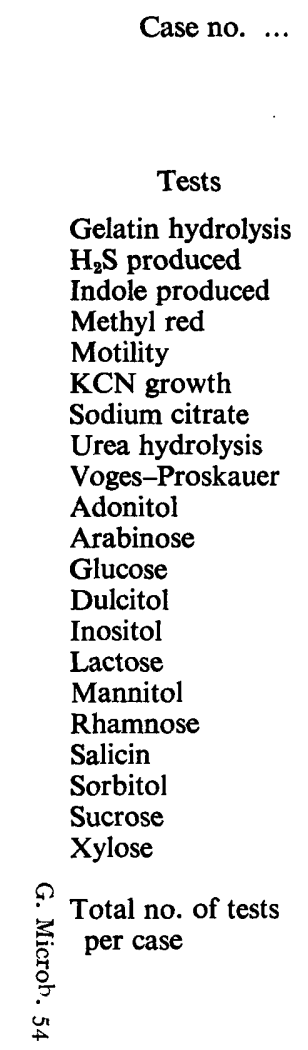
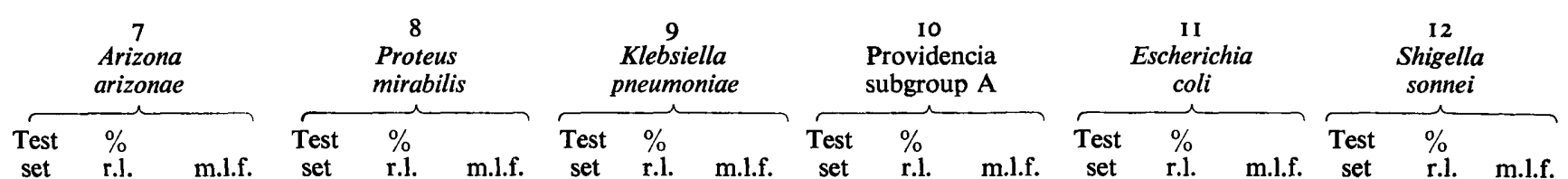

\begin{tabular}{|c|c|c|}
\hline 4 & . & . \\
\hline I & . & . \\
\hline I & . & . \\
\hline · & . & . \\
\hline I & . & . \\
\hline 3 & . & . \\
\hline . & . & . \\
\hline I & . & . \\
\hline • & . & . \\
\hline . & . & . \\
\hline 2 & • & . \\
\hline 3 & - & . \\
\hline 2 & $50 \cdot 0$ & 0.026 \\
\hline 4 & $100 \cdot 0$ & 0.0007 \\
\hline I & . & . \\
\hline 3 & . & . \\
\hline 3 & $100 \cdot 0$ & 0.026 \\
\hline · & . & - \\
\hline 1 & 100.0 & 1.00 \\
\hline • & $\cdot$ & . \\
\hline
\end{tabular}

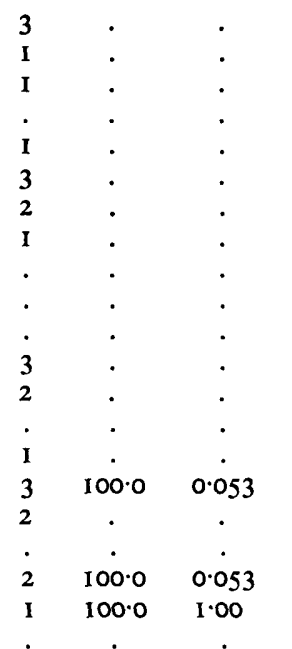$$
14
$$$$
9
$$

9

* No further tests available with discriminating power between the suspects printed.

$\dagger$ Bold final scores mean that at least one other suspect had the same score or greater. 
as well as an erroneous one (motile strain). The effect of the correct coding would have been to leave the relative position of the correct answer unchanged, but its relative likelihood would have risen to $20 \%$, and its modal likelihood fraction to 0.052 .

The two previous criticisms make it clear that the practical use of this technique requires rigorous data-checking, and also requires a criterion for deciding the sequence in which tests are to be carried out. Such a sequence will of necessity be dynamic, in that fresh tests will need to be determined at any stage on the basis of results up to that stage. To what extent the methods of Rypka et al. (1967) already referred to, or those of Gyllenberg (1964), can be used has yet to be seen, but it is possible that the lack of resolution of these methods where variable characters are concerned may render them unsuitable. A more promising approach may be to evaluate at each stage the increase either in probability difference or in probability ratio between first and second suspects for all possible outcomes of all remaining tests and then to choose the test(s) giving the greatest minimum increase - in other words, choose those tests whose most unfavourable outcome is better than that of the other tests. Whatever technique is adopted should be tested by growing strains, dividing the cultures and investigating one half by orthodox laboratory methods and the other by following the computed sequence. Only by such practical investigations can a theoretical method prove its worth.

A final criticism which can be levelled is that the procedure as given (and this is true of any study using either unaided Bayesian probability or (relative) likelihood) is incapable of recognizing a strain from outside its basic reference set. Any such strain will be identified as the member of the reference set which most resembles it, even if the resemblance is derisory.

As against the criticisms, it is true that the maximum relative likelihood choice would have had some success. Six of the twelve specimens would have been unequivocally identified, and a further three would have been among the choices with $100 \%$ relative likelihood. One case would have been identified unequivocally if it had not been for a data error, one was incapable of being identified on the test results, and one case would have been misidentified even if an erroneous test result had not been included. But a higher success rate is needed if the procedure is to be practical. Bearing in mind the points previously made, one is left with the uncomfortable feeling that good luck played its part as much as good judgement. Perhaps more realistic frequency ratios might have improved the performance in the marginal cases. But the acquisition of such data would call for a national or international effort, as has been noted in another context (Bogdanescu \& Racotta, 1967).

\section{Conclusions}

All in all, we submit that the present study, limited as it was, shows that the use of conditional probability for bacteriological identification is unlikely to prove satisfactory unless the basic data are critically evaluated beforehand and further investigations are made of the techniques of decision-making based on conditional probability. In addition, a rationale for the determination of test sequences is also needed.

This work was done while one of us (D.A.F.) was employed by Elliott Medical Automation, Ltd., and we are grateful to Dr L. C. Payne, at that time Director of the 
Medical Automation Experimental Unit, University College Hospital, for his encouragement of the study. Our thanks are due also to Colonel W. L. Kenoyer, Officer Commanding the U.S.A.F. Hospital, South Ruislip, and to Major M. T. Smith, Director of the U.S.A.F. Medical Laboratory Centre at South Ruislip, for their support and helpful interest. Above all, we are very greatly indebted to Dr S. P. Lapage, Curator of the National Collection of Type Cultures, Public Health Laboratory Service, for his continuing advice, criticism and guidance during the preparation of the manuscript. Both he and Mr W. R. Wilcox, of the Computer Trials Laboratory, Public Health Laboratory Service, to whom we are also very grateful, read and re-read the manuscript, and their comments were invaluable to us during the formative stages of this paper. Our thanks are also due to Miss G. Chambers for her patient typing and retyping of an awkward manuscript.

\section{REFERENCES}

Bergey's Manual of Determinative Bacteriology. (1957). 7th ed. Ed. by R. S. BREED, E. G. D. MuRRAX \& N. R. SMrtr. Baltimore: Williams and Wilkins Co.

BOGDANESCU, V. \& RACOTTA, R. (1967). Identification of mycobacteria by overall similarity analysis. J. gen. Microbiol. 48, III.

Boyle, J. A., Greig, W. R., Franklin, D. A., Harden, R. McG., Buchanan, W. W. \& McGirr, E. M. (1966). Construction of a model for computer-assisted diagnosis: application to the problem of non-toxic goitre. Q. Jl Med. 35, no. 140.

EDwARDs, P. R. \& EWING, W. H. (1962). Identification of Enterobacteriacae, 2nd ed. Minneapolis: Burgess Publishing Company.

Firzgerald, L. T. \& Williams, C. M. (I964). Modified program for computer diagnosis of thyroid disease. Radiology, 82, 334 .

GyllenBerg, H. G. (1964). An approach to numerical descriptions of microbial populations. Ann. Acad. Scient. fenn. Ser. A, IV. Biologica, no. 81, 2.

KaUfFMANN, F. (1954). Enterobacteriacae. Copenhagen: Ejnar Munksgaard.

Kendall, M. G. \& StuART, A. F. (1963a). The Advanced Theory of Statistics, vol. I, ch. 8. London: Charles Griffin and Company.

Kendall, M. G. \& Stuart, A. F. (1963 b). The Advanced Theory of Statistics, vol. I, p. 127.

LEDLEY, R. S. \& LuSTED, L. B. (1959). Reasoning foundations of medical diagnosis. Science, N.Y. I30, 3356.

LIPKIN, M. (1964). The likelihood concept in differential diagnosis. Perspectives in Biology and Medicine, 7,4 .

MöLLER, F. (1962). Quantitative methods in the systematics of Actinomycetales. IV. The theory and application of a probabilistic identification key. G. Microbiol, ro, 29.

PAYNE, L. C. (1963). Towards medical automation. Wld Med. Electronics, 2, I.

RYPKA, E. W., ClAPPER, W. E., Bowen, I. G. \& BABB, R. (1967). A model for the identification of bacteria. J. gen. Microbiol. 46, 407.

Warner, H. R., Toronto, A. F., Veasey, L. G. \& Stephenson, R. (I961). A mathematical approach to medical diagnosis. J. Am. med. Ass. 177, 3. 
APPENDIX

Example of program output; strain, Providencia subgroup $A$

First set of tests

$\begin{array}{lc}\quad \text { Given } & \text { Identification } \\ \text { Indol } & + \\ \text { Motility } & + \\ \mathbf{H}_{2} \mathbf{S} & - \\ \text { Urea } & - \\ \text { Sucrose } & \text { Acid + gas } \\ \text { Lactose } & \text { Acid }\end{array}$

Then, applying these results to the complete set of bacteria, the most likely are (taking either the first Io or those whose $\%$ relative likelihood is greater than $\mathrm{I} \%$, whichever is less):

$\begin{array}{cc}\begin{array}{c}\text { Relative likelihood } \\ (\%)\end{array} & \begin{array}{c}\text { Modal likelihood } \\ \text { fraction }\end{array} \\ \text { I00.000000 } & 0.026316 \\ 52.631579 & 0.105263 \\ 5.263158 & 0.005540 \\ 2.915877 & 0.005540 \\ 2.631579 & 0.000693\end{array}$

The best tests for distinguishing between these possibilities are (taking either the first six or those whose power is greater than 0.80 of the maximum power scored whichever is less):

Providence gp. (Biochem gp. I)

E. coli group

Alk./dispar group

Cloaca cloaca

Providence gp. (Biochem. gp. 2)

First and second set of tests

\begin{tabular}{lc}
\multicolumn{1}{c}{ Given } & Identification \\
Indole & + \\
Motility & + \\
$\mathrm{H}_{2} \mathrm{~S}$ & - \\
Urea & - \\
Sucrose & Acid + gas \\
Lactose & Acid \\
Mannitol & No change \\
Arabinose & No change
\end{tabular}

Then, applying these results to the complete set of bacteria, the most likely are (taking either the first 10 or those whose $\%$ relative likelihood is greater than $\mathrm{I} \%$, whichever is less):

Providence gp. (Biochem. gp. I)

Providence gp. (Biochem. gp. 2)

$\begin{array}{cc}\begin{array}{c}\text { Relative } \\ \text { likelihood ( } \%)\end{array} & \begin{array}{c}\text { Modal likelihood } \\ \text { fraction }\end{array} \\ \text { 100.000000 } & 0.026316 \\ \text { I.31 } 5789 & 0.000693\end{array}$


The best tests for distinguishing between these possibilities are (taking either the first six or those whose power is greater than 0.80 of the maximum power scored, whichever is less):

$\begin{array}{cc} & \begin{array}{c}\text { Relative } \\ \text { discriminating } \\ \text { power }\end{array} \\ \text { Glucose: } & \mathbf{I} \cdot 00000\end{array}$

First, second and third set of tests

$\begin{array}{lc}\quad \text { Given } & \text { Identification } \\ \text { Indole } & + \\ \text { Motility } & + \\ \mathrm{H}_{2} \mathrm{~S} & - \\ \text { Urea } & - \\ \text { Glucose } & \text { Acid + gas } \\ \text { Sucrose } & \text { Acid + gas } \\ \text { Lactose } & \text { Acid } \\ \text { Mannitol } & \text { No change } \\ \text { Arabinose } & \text { No change }\end{array}$

Then, applying these results to the complete set of bacteria, the most likely are (taking either the first eight or those whose $\%$ relative likelihood is greater than $\mathrm{I} \%$, whichever is less):

$\begin{array}{ccc} & \begin{array}{c}\text { Relative likelihood } \\ (\%)\end{array} & \begin{array}{c}\text { Modal likelihood } \\ \text { fraction }\end{array} \\ \begin{array}{c}\text { Providence gp. (Biochem. gp. I) } \\ \text { (only one bacterium) }\end{array} & 100.000000 & 0.026316\end{array}$

\section{Notes}

(a) The names of tests and organisms used in the output were working names, and no attempt was made to ensure that these conformed to internationally accepted nomenclature. The titles 'Providence gp. (Biochem. gp. I)' and 'Providence gp. (Biochem. gp. 2)' refer to Providencia subgroup $A$ and Providencia subgroup $B$, respectively. The other titles will be self-evident.

(b) In the programme, the 'discriminating power' for any test over a set of bacteria was scaled by the maximum for the tests being considered, and referred to as 'relative discriminating power'. 